\title{
Cluster Size Dependent Interaction of Free Manganese Oxide Clusters with Acetic Acid and Methyl Acetate
}

Sandra M. Lang, ${ }^{\text {a }}$ Thorsten M. Bernhardt, ${ }^{a}$ Joost M. Bakker, ${ }^{b}$ Robert N. Barnett, ${ }^{c}$ Uzi Landman*c

a Institute of Surface Chemistry and Catalysis, University of Ulm, Albert-Einstein-Allee 47,

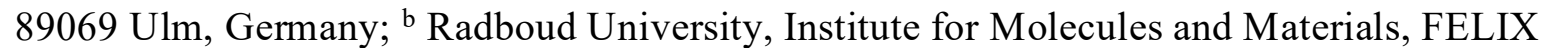
Laboratory, Toernooiveld 7, 6525 ED Nijmegen, The Netherlands; ${ }^{\mathrm{c}}$ School of Physics, Georgia Institute of Technology, Atlanta, GA 30332-0430, USA

\section{Mass Spectra}

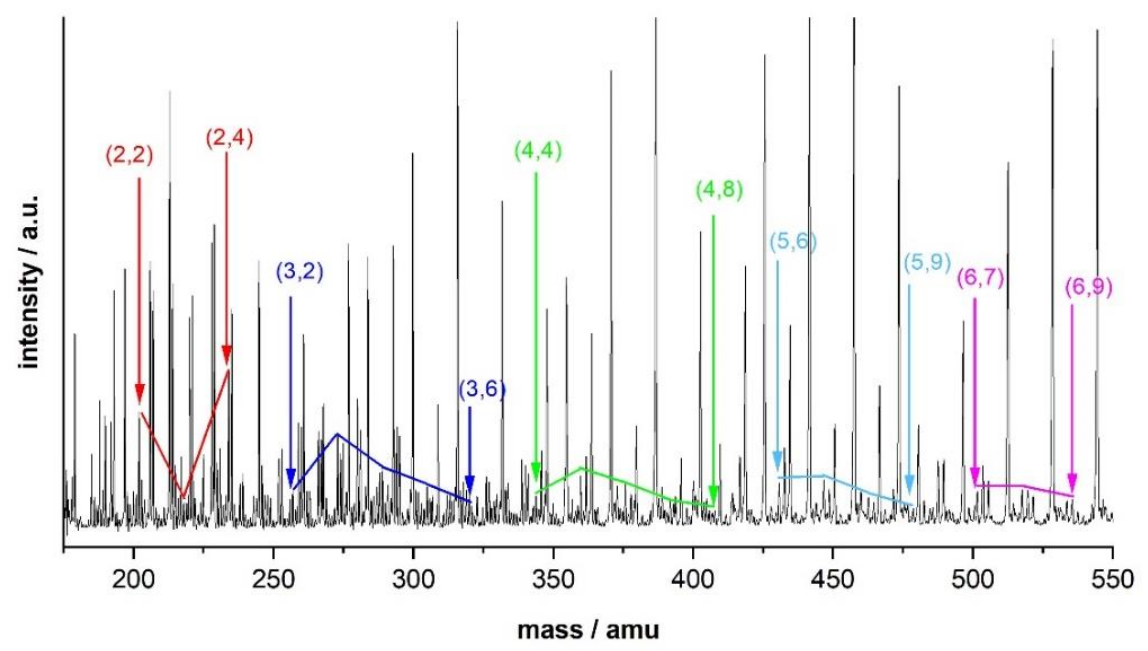

Figure S1: Ion mas distribution obtained after introducing $4 \% \mathrm{HOAc} / \mathrm{He}$ into the flow tube reactor. The peaks labeled $(x, y)$ correspond to the products $\mathrm{Mn}_{x} \mathrm{O}_{y}(\mathrm{HOAC})^{+}$.

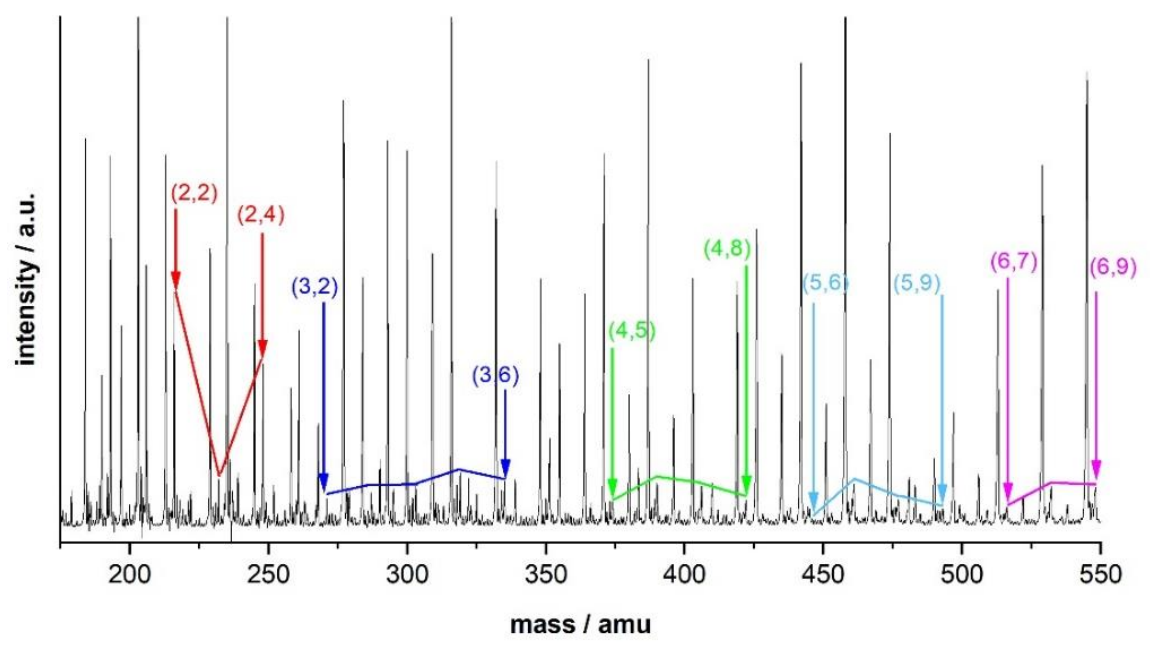

Figure S2: Ion mas distribution obtained after introducing $0.5 \% \mathrm{MeOAc} / \mathrm{He}$ into the flow tube reactor. The peaks labeled $(x, y)$ correspond to the products $\mathrm{Mn}_{\mathrm{x}} \mathrm{O}_{\mathrm{y}}(\mathrm{MeOAc})^{+}$. 
2. Vibrational Spectra of $\mathrm{Mn}_{2} \mathrm{O}_{2}(\mathrm{HOAC})^{+}$Isomers

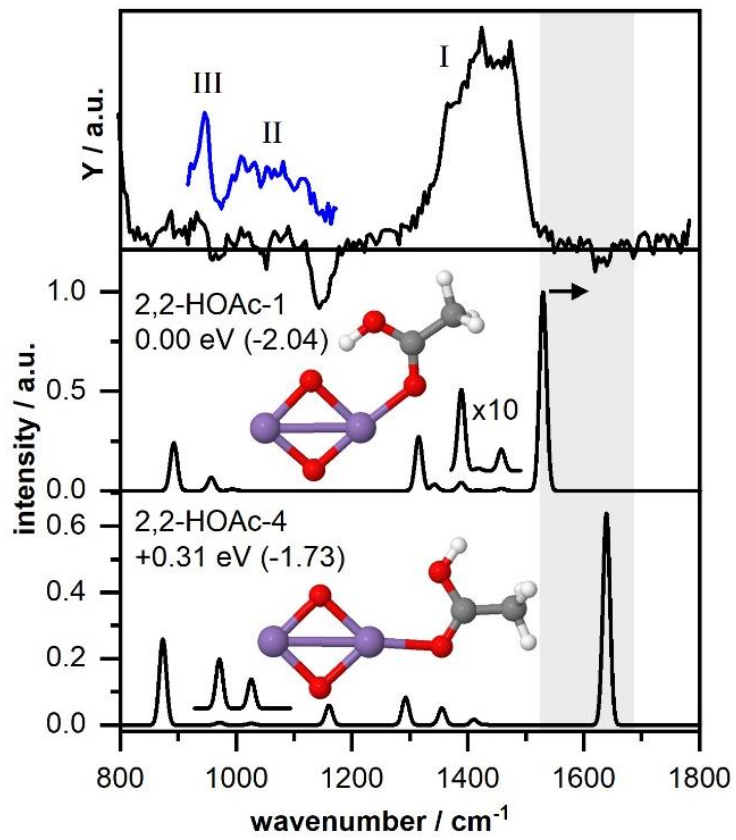

Figure S3: IR-MPD spectrum of $\mathrm{Mn}_{2} \mathrm{O}_{2}(\mathrm{HOAc})^{+}$together with the calculated spectra of two isomeric structures (all $\mu=9$ ) with trans- and cis-bound HOAc, respectively. The gray bar is added to guide the eye. All energies are given relative to the encounter complex 2,2-HOAc-1. The numbers in brackets denote the energies relative to $\mathrm{Mn}_{2} \mathrm{O}_{2}{ }^{+}+\mathrm{HOAc}$. $\mathrm{Mn}, \mathrm{O}, \mathrm{C}$, and $\mathrm{H}$ atoms are depicted as purple, red, gray, and white spheres, respectively. 


\section{Vibrational Spectra of $\mathrm{Mn}_{2} \mathrm{O}_{4}(\mathrm{HOAc})^{+}$Isomers}

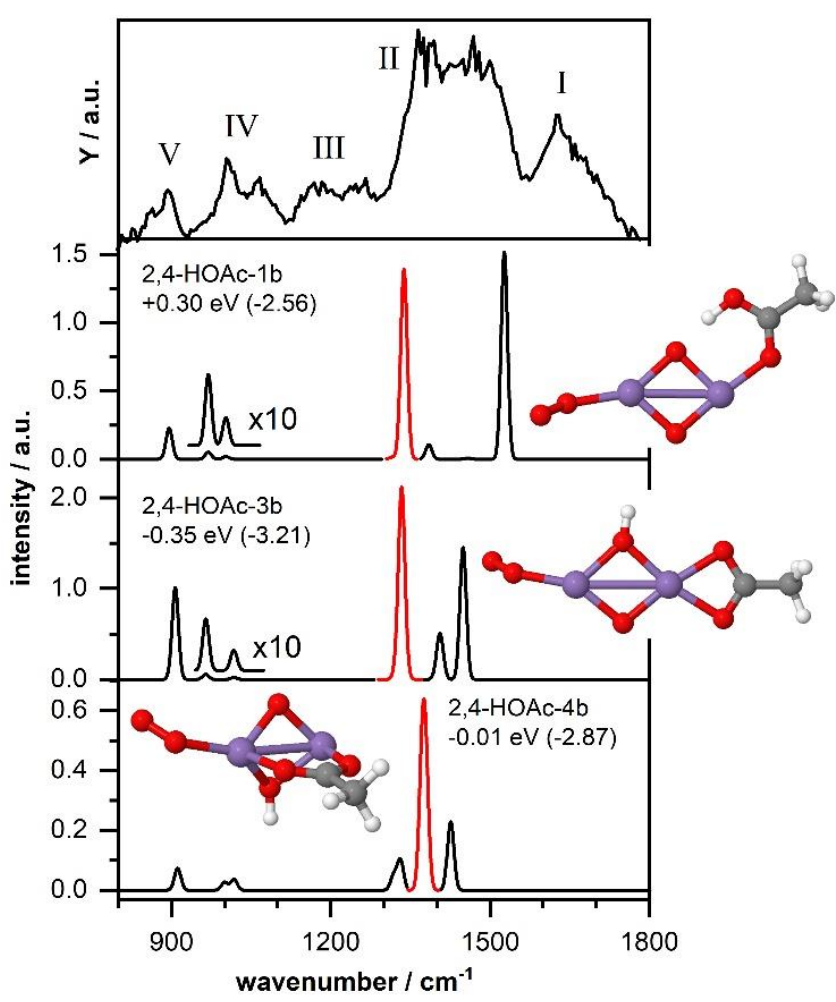

Figure S4: IR-MPD spectrum of $\mathrm{Mn}_{2} \mathrm{O}_{4}(\mathrm{HOAc})^{+}$together with the calculated spectra of three isomeric structures (all $\mu=7$ ) with $\eta^{1}$-bound $\mathrm{O}_{2}$. All energies are given relative to the encounter complex 2,4HOAc-1 (cf. Figure 4 of the main text). The numbers in brackets denote the energies relative to $\mathrm{Mn}_{2} \mathrm{O}_{4}{ }^{+}$ + HOAc. $\mathrm{Mn}, \mathrm{O}, \mathrm{C}$, and $\mathrm{H}$ atoms are depicted as purple, red, gray, and white spheres, respectively. 


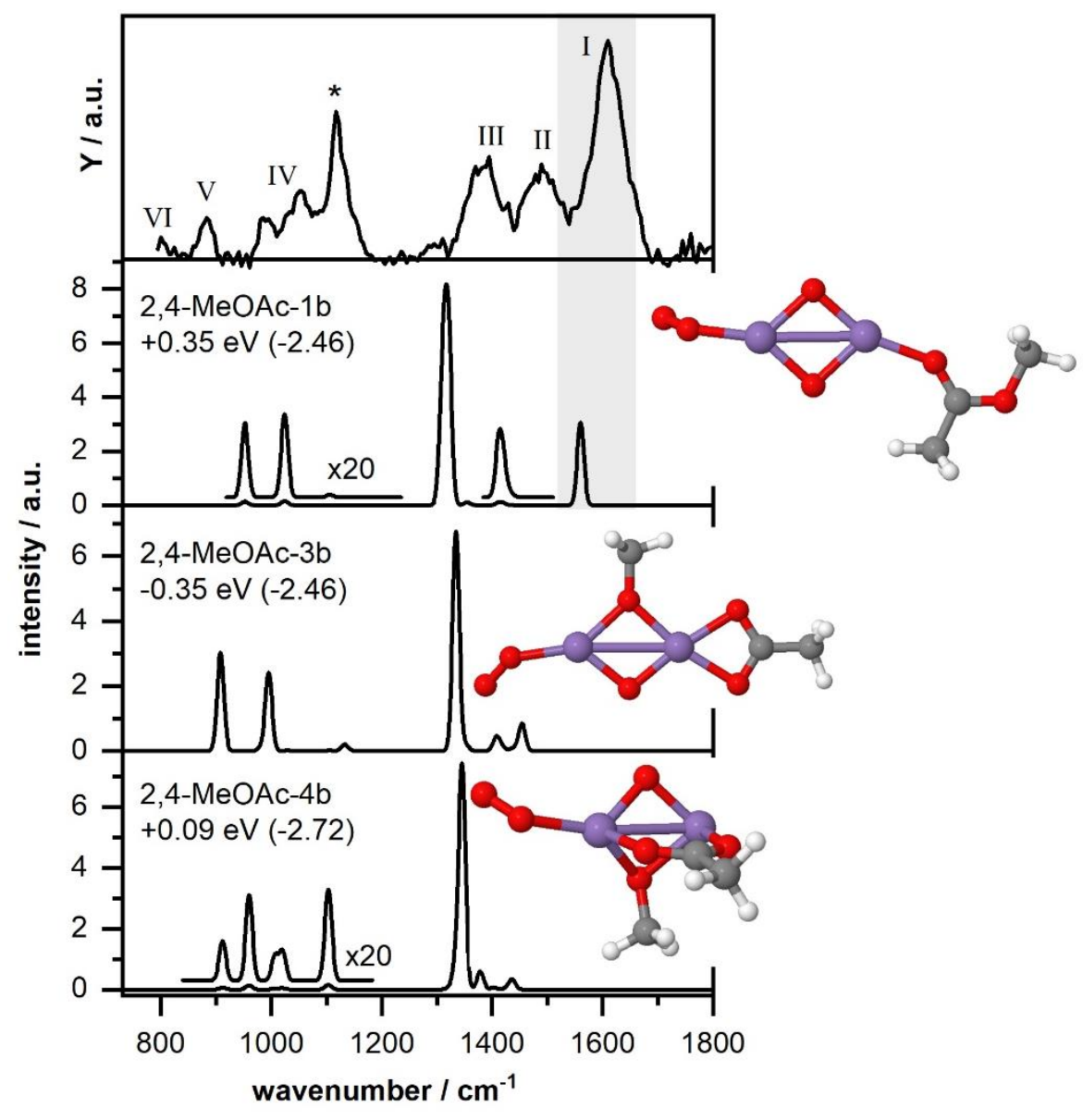

Figure S5: IR-MPD spectrum of $\mathrm{Mn}_{2} \mathrm{O}_{4}(\mathrm{MeOAc})^{+}$together with the calculated spectra of three isomeric structures (all $\mu=7$ ) with $\eta^{1}$-bound $\mathrm{O}_{2}$. The gray bar is added to guide the eye. All energies are given relative to the encounter complex 2,4-MeOAc-1 (cf. Figure 7 of the main text). The numbers in brackets denote the energies relative to $\mathrm{Mn}_{2} \mathrm{O}_{4}{ }^{+}+\mathrm{MeOAc}$. $\mathrm{Mn}, \mathrm{O}, \mathrm{C}$, and $\mathrm{H}$ atoms are depicted as purple, red, gray, and white spheres, respectively. 